\title{
American ginseng (Panax quinquefolius) administration does not affect performance of the Roche COBAS Ampliprep/Taqman HIV-1 RNA assay
}

\author{
Rahul P Bakshi', Todd T Brown ${ }^{2}$, Antoine Simmons ${ }^{3}$, Chun-Su Yuan ${ }^{4}$, Brent A Bauer ${ }^{5}$, Jeff A Sloan ${ }^{6}$ \\ and Adriana Andrade ${ }^{7^{*}}$
}

\begin{abstract}
Background: Previous data indicate that purified components of ginseng can inhibit HIV reverse transcriptase in vitro, suggesting that ginseng components in plasma may interfere with HIV-1 RNA detection assays.

Methods: Pre- and post-dose plasma from three volunteers dosed with $3000 \mathrm{mg}$ American ginseng was spiked with HIV and analyzed by the Roche COBAS Ampliprep/Taqman v2.0 HIV-1 RNA assay.

Results: Presence of American ginseng had no significant effect on measured HIV-1 RNA concentration. Variation within pre- and post-dose plasma pair was insignificant and within assay performance limits.

Conclusion: Plasma from subjects dosed with 3000 mg American ginseng does not interfere with the Roche COBAS Ampliprep/Taqman v2.0 HIV-1 RNA assay. This implies that in vitro inhibition of HIV reverse transcriptase by American ginseng components is unlikely to be clinically relevant.
\end{abstract}

\section{Background}

American ginseng is used to ameliorate HIV-associated fatigue [1]. Recent reports have indicated that protein components of Asian ginseng (Panax ginseng and Panax notoginseng) can inhibit HIV-1 reverse transcriptase and other polymerases in vitro [2,3]. Data from the literature suggests that it is unlikely that protein components of orally-dosed ginseng are bioavailable at relevant concentrations, or survive the processing required to quantify plasma HIV-1 RNA concentrations [4,5]. However, these findings raised concerns that ginseng components may interfere with reverse transcriptase-dependent assays used to determine plasma HIV-1 RNA concentration, and potentially confound clinical management of this disease.

We hypothesized that standardized American ginseng would not affect the performance of the Roche COBAS Ampliprep/Taqman v2.0 HIV-1 RNA assay (Limit of

\footnotetext{
* Correspondence: aandrade@jhmi.edu

${ }^{7}$ Division of Infectious Diseases, Johns Hopkins University, 1830 E. Monument Street, Suite 8074, Baltimore, MD 21205, USA

Full list of author information is available at the end of the article
}

Detection 20 copies/ml) used in clinical practice to quantify plasma HIV-1 RNA. American ginseng was selected for this experiment because we used this dietary supplement in our previous studies [6,7]. We tested our hypothesis by measuring the performance of the Roche COBAS Ampliprep/Taqman v2.0 HIV-1 RNA assay [4] in plasma of volunteers receiving high-dose American ginseng.

\section{Methods}

De-identified archived plasma samples from healthy volunteers and HIV-infected patients were utilized with Johns Hopkins Medicine Institutional Review Board approval. Test samples had been archived from a previous study (NCT01136928, www.clinicaltrials.gov) in healthy volunteers dosed orally with $3000 \mathrm{mg}$ daily of American ginseng for 14 days. Selection of a 14-day dosing period was based on the principle that it can take up to two weeks for maximal induction of drug metabolizing enzymes involved in the biotransformation of pharmacological compounds. The American ginseng capsules used in our previous studies were made from ground root from 
a single lot provided by the Ginseng Board of Wisconsin (Wasau, WI). The sample of American ginseng was standardized to $\geq 5 \%$ total ginsenosides, plant steroids of the saponin class that are thought to be the active ingredients of this dietary supplement [8]. The following ginsenoside concentrations were detected by HPLC analysis: Rg1 1.02 $\mathrm{mg} / \mathrm{g}$, Re $14.81 \mathrm{mg} / \mathrm{g}$, Rb1 $34.28 \mathrm{mg} / \mathrm{g}$, Rc $4.69 \mathrm{mg} / \mathrm{g}$, Rb2 $0.65 \mathrm{mg} / \mathrm{g}$, Rb3 $0.98 \mathrm{mg} / \mathrm{g}$, and Rd $6.65 \mathrm{mg} / \mathrm{g}$. The sample was also tested for common contaminants including bacteria, fungi, and heavy metals. Ginsenoside plasma concentrations were not measured.

Plasma samples obtained at 4 hours post-dose were utilized for the study since it has been demonstrated that ginsenoside $\mathrm{Rb} 1$ concentration peaks approximately $4 \mathrm{~h}$ post-dose [9]. HIV RNA-containing plasma was obtained from the Johns Hopkins Pathology plasma bank. One hundred twenty $\mu \mathrm{l}$ of plasma with HIV RNA concentration of 2,177,772 copies/ml was added to $1080 \mu \mathrm{l}$ test plasma without and with American ginseng. The high HIV RNA concentration was selected to discern between a potential effect of American ginseng on the Cobas assay versus a dilution effect. Matched sample pairs from three volunteers were utilized for the test. We selected three plasma samples of American ginseng based on the assumption that if the assay inhibition was relevant and robust, the effect of American ginseng would have been seen in a few samples with this high dose of American ginseng.

Plasma HIV-1 RNA concentration in these spiked samples was determined using the Roche COBAS Ampliprep/ Taqman v2.0 HIV-1 RNA assay with an internal control (Limit of Detection 20 copies/ml).

\section{Results and discussion}

In all three plasma pairs (Table 1), the presence of American ginseng had no significant effect on measured plasma HIV-1 RNA concentrations. $\log _{10}$ plasma HIV-1 RNA ranged from 6.02 to 6.09 . This variation is negligible and within assay performance limits [4].

These results establish that the Roche COBAS Ampliprep/Taqman v2.0 HIV-1 RNA assay does not suffer from interference when used with plasma from subjects receiving American ginseng.

Our study had some limitations: 1) The American ginseng sample tested in our experiments was standardized to $\geq 5 \%$ total ginsenosides and also tested for potential contaminants, as recommended in the literature. Therefore, our results cannot be generalized to other studies that do not follow these recommended standardization procedures; 2) Because ginsenosides or other American ginseng components were not measured in the test samples, we are uncertain about the concentration of American ginseng components in systemic circulation at the time the plasma was sampled. However, previous pharmacokinetic studies [9] have suggested that peak ginsenoside plasma concentrations should occur around the time point we examined; 3) The lack of effect on the COBAS plasma HIV RNA assay described here might not be generalizable to other species, formulations and plant parts of ginseng. Ginseng consists of at least 10 species within the genus Panax that are indigenous to Asia (Chinese, Japanese, and Sanchi ginseng) and North America (Panax quinquefolius) [8]. There are more than 30 identified ginsenosides, which vary in number and concentration from one species of ginseng to another [8]. These variances in ginsenoside concentrations could potentially lead to a different effect on the performance of HIV RNA assays depending on the species of ginseng being tested. Also, the roots, berries, and leaves of the ginseng plant are known to contain different concentrations of ginsenosides. Since our study used powdered ginseng root, the lack of effect of other parts of the ginseng plant on this viral assay would need to be verified. In addition, difference in ginseng formulations, including dissimilarity in excipient content, is another potential factor that could potentially lead to different effects on the performance of HIV RNA assays. 4) Finally, our experiment tested samples from subjects taking $3000 \mathrm{mg}$ daily of American ginseng for 14 days, which was the highest dose used in one of our previous studies (NCT01136928, www. clinicaltrials.gov). The effects of higher doses or treatment duration with American ginseng on viral assays would require further investigation.

\section{Conclusions}

In conclusion, plasma from subjects taking high-dose standardized American ginseng did not interfere with the Roche COBAS Ampliprep/Taqman v2.0 HIV-1 RNA assay performance. These results also suggest that ginseng induced HIV-1 reverse transcriptase inhibition demonstrated in vitro $[2,3]$ is unlikely to be clinically relevant. This finding provides much needed data on the effects of dietary supplements on laboratory tests commonly used

Table 1 Effect of American ginseng on plasma HIV RNA measurement

\begin{tabular}{|c|c|c|c|c|c|c|}
\hline Sample set & $\begin{array}{c}1 \\
\text { - ginseng }\end{array}$ & $\begin{array}{c}2 \\
+ \text { ginseng }\end{array}$ & $\begin{array}{c}3 \\
\text { - ginseng }\end{array}$ & + ginseng & - ginseng & + ginseng \\
\hline HIV-RNA (copies/ml) & 1109720 & 1122310 & 1218900 & 1165710 & 1032900 & 1191440 \\
\hline HIV RNA $\left(\log _{10}\right)$ & 6.05 & 6.05 & 6.09 & 6.07 & 6.02 & 6.08 \\
\hline
\end{tabular}

Roche COBAS Ampliprep/Taqman v2.0 HIV-1 RNA assay (Limit of detection 20 copies $/ \mathrm{ml}$ ). 
in the management of HIV-infected patients, an area of significant concern since the use of herbals and botanicals is common in the HIV-infected community in the United States and in other countries.

\section{Competing interests}

American ginseng powdered root used in our previous studies was donated by the Ginseng Board of Wisconsin. Otherwise, the authors declare that they have no competing interests.

\section{Authors' contributions}

Designed research, analyzed research and wrote the paper - RPB, TTB, AS, $\mathrm{CY}, \mathrm{BB}, \mathrm{JS}, \mathrm{AA}$; Conducted research - RPB, AS. All authors read and approved the final manuscript.

\section{Acknowledgements}

This study was funded by AT005526-01. Funders had no role in study design, or collection, analysis and interpretation of data.

\section{Author details}

'Department of Medicine, Division of Clinical Pharmacology, Johns Hopkins University, Osler 503, 600 N Wolfe Street, Baltimore, MD 21287, USA. ${ }^{2}$ Department of Medicine, Division of Endocrinology, Diabetes, and Metabolism, Johns Hopkins University, 1830 East Monument Street, Suite 333, Baltimore, MD 21287, USA. ${ }^{3}$ Department of Pathology, Johns Hopkins University, 600 North Wolfe Street Meyer Bldg, Rm B130, Baltimore, MD 21287, USA. ${ }^{4}$ Department of Anesthesia and Critical Care, Tang Center for Herbal Medicine Research, Department of Anesthesia \& Critical Care Pritzker School of Medicine, University of Chicago, 5841 S. Maryland Avenue, MC 4028, Chicago, II 60637, USA. ${ }^{5}$ Department of Medicine, Mayo Clinic, 200 1st St SW, Rochester, MN 55905, USA. ${ }^{6}$ Department of Health Sciences Research, Mayo Clinic, Harwick 8-29, 200 First Street SW, Rochester, MN 55905, USA. ${ }^{7}$ Division of Infectious Diseases, Johns Hopkins University, 1830 E. Monument Street, Suite 8074, Baltimore, MD 21205, USA.

Received: 2 April 2014 Accepted: 15 October 2014

Published: 31 October 2014

\section{References}

1. Standish L, Greene KB, Bain S, Reeves C, Sanders F, Wines RC, Turet P, Kim JG, Calabrese C: Alternative medicine use in HIV-positive men and women: demographics, utilization patterns and health status. AIDS care 2001, 13(2):197-208.

2. Lam SK, Ng TB: A xylanase from roots of sanchi ginseng (Panax notoginseng) with inhibitory effects on human immunodeficiency virus-1 reverse transcriptase. Life Sci 2002, 70(25):3049-3058.

3. Ng TB, Wang H: Panaxagin, a new protein from Chinese ginseng possesses anti-fungal, anti-viral, translation-inhibiting and ribonuclease activities. Life Sci 2001, 68(7):739-749.

4. Pas S, Rossen JW, Schoener D, Thamke D, Pettersson A, Babiel R, Schutten M: Performance evaluation of the new Roche Cobas AmpliPrep/Cobas TaqMan HIV-1 test version 2.0 for quantification of human immunodeficiency virus type 1 RNA. J Clin Microbiol 2010, 48(4):1195-1200.

5. Qi LW, Wang CZ, Du GJ, Zhang ZY, Calway T, Yuan CS: Metabolism of ginseng and its interactions with drugs. Curr Drug Metab 2011, 12(9):818-822.

6. Andrade AS, Hendrix C, Parsons TL, Caballero B, Yuan CS, Flexner CW, Dobs AS, Brown TT: Pharmacokinetic and metabolic effects of American ginseng (Panax quinquefolius) in healthy volunteers receiving the HIV protease inhibitor indinavir. BMC Complement Altern Med 2008, 8:50.

7. Barton DL, Soori GS, Bauer BA, Sloan JA, Johnson PA, Figueras C, Duane S, Mattar B, Liu H, Atherton PJ, Christensen B, Loprinzi CL: Pilot study of Panax quinquefolius (American ginseng) to improve cancer-related fatigue: a randomized, double-blind, dose-finding evaluation: NCCTG trial N03CA. Support Care Cancer off J Multinational Assoc Support Care Cancer 2010, 18(2):179-187.
8. Attele AS, Wu JA, Yuan CS: Ginseng pharmacology: multiple constituents and multiple actions. Biochem Pharmacol 1999, 58(11):1685-1693.

9. Wang $C Z$, Kim KE, Du GJ, Qi LW, Wen XD, Li P, Bauer BA, Bissonnette MB, Musch MW, Chang EB, Yuan CS: Ultra-performance liquid chromatography and time-of-flight mass spectrometry analysis of ginsenoside metabolites in human plasma. Am J Chin Med 2011, 39(6):1161-1171.

doi:10.1186/1472-6882-14-427

Cite this article as: Bakshi et al:: American ginseng (Panax quinquefolius) administration does not affect performance of the Roche COBAS Ampliprep/Taqman HIV-1 RNA assay. BMC Complementary and Alternative Medicine 2014 14:427.

\section{Submit your next manuscript to BioMed Central and take full advantage of:}

- Convenient online submission

- Thorough peer review

- No space constraints or color figure charges

- Immediate publication on acceptance

- Inclusion in PubMed, CAS, Scopus and Google Scholar

- Research which is freely available for redistribution 